\title{
Reflexiones sobre el proyecto Auto-Demarcación y EtnoCartografía de las Tierras y Hábitats Jodï y Eñepa
}

Reflections on a Collaborative Project of Land Demarcation and

Ethnocartographic Documentation of Jodi and Eñepa Lands and Habitats, Venezuelan Amazon

Reflexions autour du projet d'auto-démarcation et d'ethnocartographie des terres et habitats Jodï et Eñepa

Stanford Zent, Egleé L. Zent, Lucas Juae Mölö y Pablo Chonokó

\section{(2) OpenEdition}

\section{Journals}

Edición electrónica

URL: http://journals.openedition.org/ethnoecologie/2670

DOI: 10.4000/ethnoecologie.2670

ISSN: 2267-2419

Editor

Laboratoire Eco-anthropologie et Ethnobiologie

\section{Referencia electrónica}

Stanford Zent, Egleé L. Zent, Lucas Juae Mölö et Pablo Chonokó, « Reflexiones sobre el proyecto AutoDemarcación y EtnoCartografía de las Tierras y Hábitats Jodi y Eñepa », Revue d'ethnoécologie [En ligne], 9 | 2016, mis en ligne le 01 juillet 2016, consulté le 01 mai 2019. URL : http://journals.openedition.org/ ethnoecologie/2670; DOI : 10.4000/ethnoecologie.2670

Este documento fue generado automáticamente el 1 mayo 2019.

\section{cc) (†)}

Revue d'ethnoécologie est mis à disposition selon les termes de la licence Creative Commons Attribution - Pas d'Utilisation Commerciale - Pas de Modification 4.0 International. 


\title{
Reflexiones sobre el proyecto Auto- Demarcación y EtnoCartografía de las
} Tierras y Hábitats Jodï y Eñepa

\author{
Reflections on a Collaborative Project of Land Demarcation and \\ Ethnocartographic Documentation of Jodi and Eñepa Lands and Habitats, \\ Venezuelan Amazon \\ Reflexions autour du projet d'auto-démarcation et d'ethnocartographie des \\ terres et habitats Jodï et Eñepa
}

Stanford Zent, Egleé L. Zent, Lucas Juae Mölö y Pablo Chonokó

\section{NOTA DEL AUTOR}

Trabajo realizado junto con los miembros de las comunidades de Kayamá y Caño Iguana, Estados Bolívar y Amazonas, Venezuela

\section{Introducción}

1 Este texto ofrece algunas reflexiones a partir de nuestra experiencia en el proyecto AutoDemarcación y Etnocartografía de los Habitats Jodï y Eñepa. Este proyecto tuvo como objetivo demarcar las tierras reconocidas como suyas por los pueblos Jodï y Eñepa, a través de la elaboración de un mapa, y la preparación de toda la documentación requerida por el Estado venezolano con el fin de solicitar títulos de propiedad colectiva étnicos que les den derechos territoriales ancestrales consuetudinarios pero definitivos legales contemporáneos. Los Jodï y Eñepa son grupos indígenas que han habitado zonas selváticas, sabaneras y montañosas en los estados Amazonas y Bolívar de Venezuela desde tiempos antiguos hasta la actualidad y todavía conservan culturas y estilos de vida en 
gran medida independientes de las sociedades nacional y global. La posibilidad de reivindicar los derechos sobre la tierra de los pueblos indígenas en Venezuela se convirtió en pilar importante de la política de justicia social enmarcada en la Constitución Bolivariana de 1999, en su Capítulo VIII, artículo 119. En 2001, se establecieron las bases jurídicas e institucionales para la realización de este objetivo a través de la Ley de Demarcación y Garantía del Hábitat y Tierras de los Pueblos Indígenas (Gaceta Oficial Año CXXVIII, IV No. 37.118, de enero de 2001) y el Decreto Presidencial Nro. 1392, en donde se crea la Comisión Nacional de Demarcación del Hábitat y Tierras de los Pueblos y Comunidades Indígenas (CNDHTI) (Gaceta Oficial Año CXXVIII, x No. 37.257, de agosto de 2001). En 2003-2004, fueron instaladas las comisiones Regionales de Demarcación en los estados de ocupación indígena y se formuló la primera reglamentación de los requisitos y procedimientos para la apertura y evaluación de los expedientes comunitarios o étnicos de demarcación. En 2005, se promulgó la Ley Orgánica de Pueblos Indígenas (LOPI); en el Título II, Capítulos III y IV, artículos 23-47 de este documento se definen con mayor detalle y exhaustividad todas las disposiciones, responsabilidades, procedimientos y criterios acerca del proceso de demarcación y titulación legal de las tierras indígenas.

2 La participación protagónica de la población indígena en este proceso fue ratificada a través de la designación de representantes indígenas en las Comisiones Nacional y Regionales, la organización de talleres de divulgación de información en las regiones con población indígena y, más importante, la inclusión de procesos de autodemarcación de hábitats y tierras, llevados a cabo por una comunidad o pueblo particular según su propia visión y criterio, como vía legítima de solicitar el derecho. El proyecto de autodemarcación Jodï y Eñepa nació como respuesta a esta apertura y la promesa de corregir la tendencia histórica de invasión y apropiación progresiva de tierras indígenas desde el comienzo de la colonización americana hasta los tiempos recientes. Sin embargo, en el caso del proyecto mencionado, más allá de simplemente producir un mapa o definir las fronteras territoriales, el reto consistió en representar las etnocartografías profundas que representen con mayor propiedad las nociones de territorio y territorialidad de estos grupos étnicos.

3 Concebimos a la etnocartografía en términos amplios como todo lo que tiene que ver con la construcción cultural del paisaje en sus múltiples aspectos: la geo-referenciación de las tierras, incluyendo no solamente los linderos sino todos los sitios y zonas de importancia cultural dentro de estos límites, la clasificación de las unidades eco-tópicas del ambiente local (Figura 1), la toponimia y las representaciones simbólicas asociadas con los lugares, los patrones de ocupación y uso del espacio, los movimientos de individuos (Figura 2), familias y aldeas; las narrativas mítico-históricas de la gente y los otros seres y objetos de su entorno enfatizando aquella de la ocupación del espacio por personas humanas o no en la construcción del espacio, incluso propician la creación de biodiversidad (véase por ejemplo Zent y Zent 2002; Zent 2014); la cosmovisión del universo y el lugar de los seres humanos en ello (Figura 3) ${ }^{1}$. El motivo de este tipo de cobertura fue intentar demostrar en todos los niveles posibles y pensables los múltiples lazos entre estos pueblos y sus tierras, y justificar así sin dar lugar a duda sus derechos originarios y únicos sobre las tierras. 
Figura 1: Ecotopos georeferenciados por los Jodĩ y Eñepa. Cada una de estas macrocategorías incluye múltiples referentes físicos

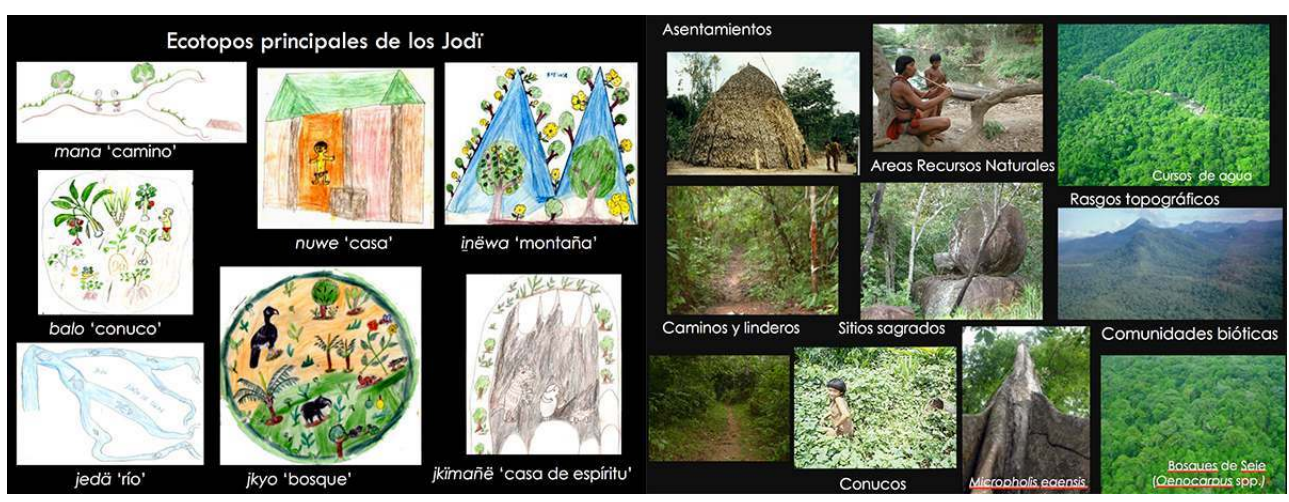

CRÉDIT : S \& E. ZENT

Figura 2: Representación georeferenciada de los movimientos de residencia principal de una sola Jodi a partir de su historia de vida

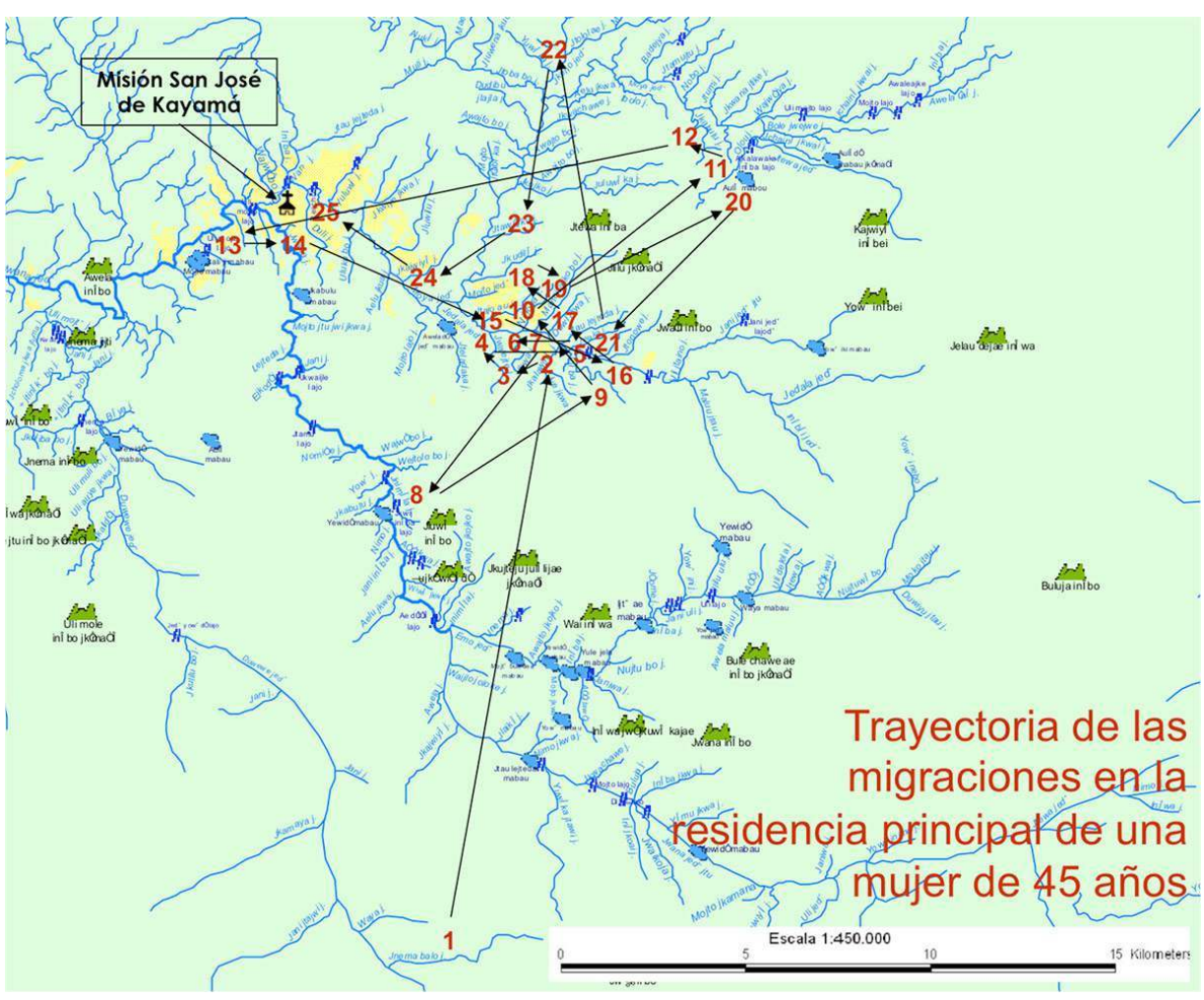




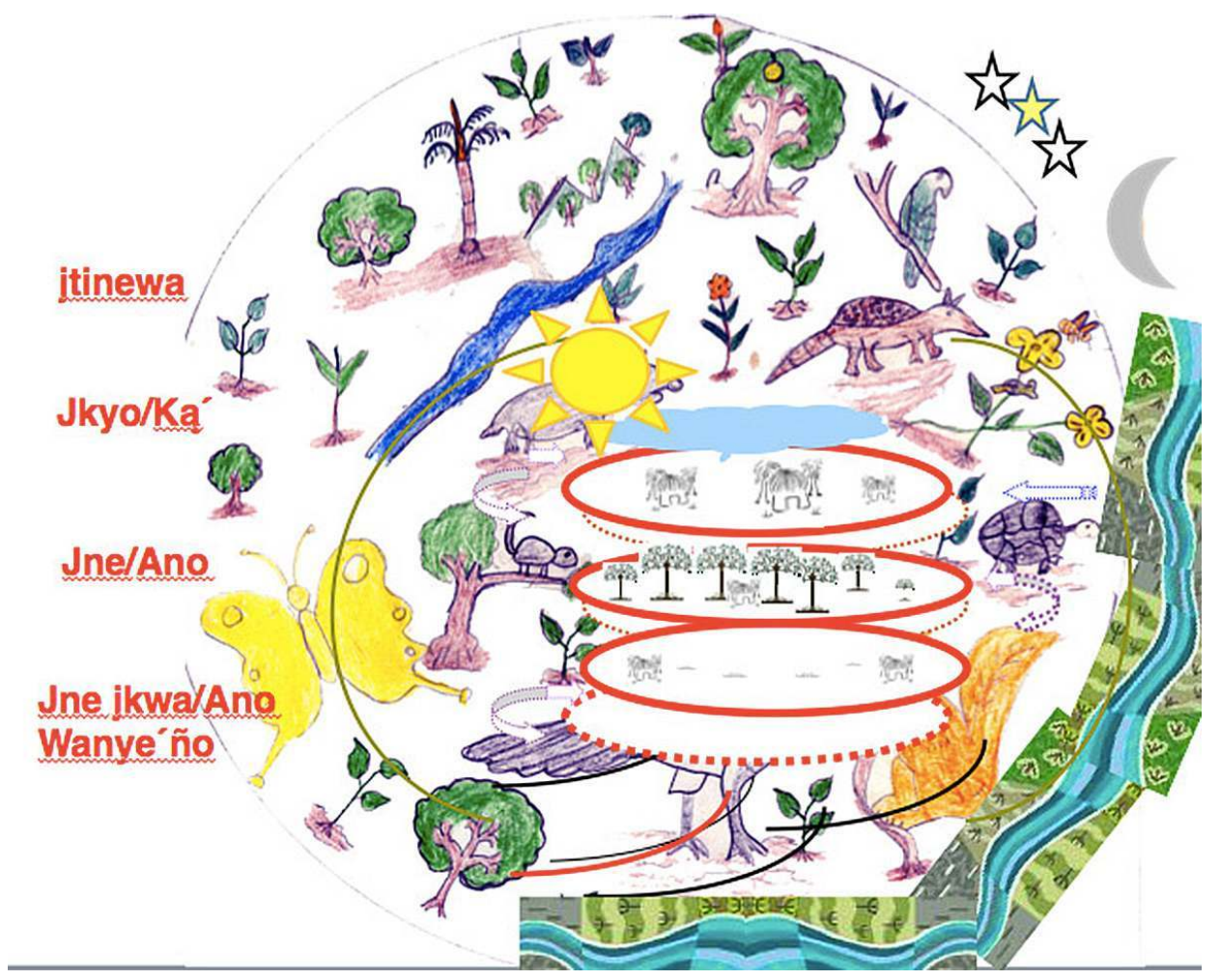

El proyecto involucraba a las comunidades Jodï de San José de Kayamá, Estado Bolívar y de Caño Iguana, Estado Amazonas y otras más pequeñas de estas dos zonas de influencia, la comunidad Eñepa de Kayamá y algunos miembros del laboratorio de Ecología Humana del Centro de Antropología del Instituto Venezolano de Investigaciones Científicas (IVIC). Por parte de los indígenas, participaron en el proyecto muchas personas de las comunidades indígenas mencionadas, de ambos géneros y todas las edades. Los coordinadores seleccionados por los Jodï fueron Lucas Juae Mölo y Héctor Liye Juae, en tanto que los Eñepa eligieron a Pablo Chonokó y José Puruwaná. ${ }^{2}$ Por parte del IVIC, además de los autores de este texto, participaron Leticia Marius y Yheicar Bernal. Aunque se inscribió el proyecto en el registro de investigaciones del IVIC, nominalmente bajo la responsabilidad de los primeros dos autores de este trabajo, la dirección ejecutiva siempre estuvo bajo el mando de los mismos indígenas. Ellos tomaron las decisiones acerca de la definición de los linderos y las zonas a ser demarcadas, se encargaron de la colecta de datos in situ y el procesamiento preliminar de datos en programas de computación mientras que los miembros del personal del IVIC actuaron fundamentalmente como asesores, técnicos e instructores en los métodos de colecta de datos y uso de la tecnología de información, incluyendo el SIG. ${ }^{3}$ La fase activa del trabajo de campo duró aproximadamente 4 años del 2001 al 2005, y, entre otras cosas, resultó en el registro (puntos GPS) de más 7000 sitios en un área de aproximadamente $8000 \mathrm{~km}^{2}$ ( Figura 4). Los mapas finales y los documentos para la apertura de los expedientes fueron preparados y entregados a las comisiones nacional y regionales respectivas a mediados del 2006. Posteriormente en 2006 se realizaron algunas modificaciones a los expedientes para cumplir con los (nuevos) formatos y requisitos estipulados. Durante los últimos 10 años (2007-2016), hemos hecho un seguimiento intermitente pero sostenido de las solicitudes, averiguando periódicamente en las instancias oficiales acerca del estatus de 
las mismas, acompañando a las comisiones oficiales en los viajes para verificar los datos suministrados, preparando documentación nueva o re-entregando los mismos materiales de nuevo a las autoridades competentes (la más reciente en noviembre de 2014) y elaborando informes o difundiendo información para otros interesados. Así, el proyecto no se ha cerrado todavía, aunque ha entrado una fase latente, y no se acabará hasta que se logre la titulación de tierra definitiva a los Jodï y Eñepa. Para más información sobre el origen, objetivos, métodos, organización y resultados de este proyecto, sugerimos la lectura de: Zent et al. 2004; Zent y Zent 2006-2008; Zent et al. 2011.

Figura 4: Registrando coordenadas (izquierda) y Hoja de datos de campo (derecha)
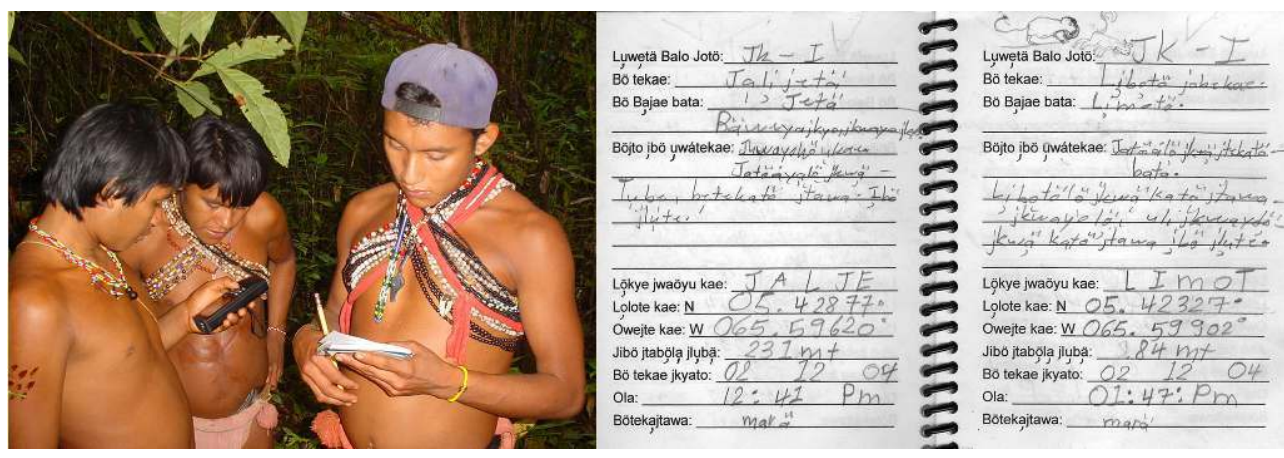

CRÉDIT : S \& E. ZENT

El presente trabajo tiene como objetivo compartir algunas lecciones que hemos ido aprendiendo durante el transcurso de esta experiencia de colaboración entre actores académicos (miembros de la comunidad científica) y locales (miembros de las comunidades indígenas), que podrían servir como insumo intelectual y práctico a aquellos que están emprendiendo proyectos similares. Las actividades de demarcación y mapeo comunitario de tierras habitadas por poblaciones indígenas han aumentado vertiginosamente en las últimas décadas, tanto en Venezuela como en otros países y regiones, y podemos anticipar que esta tendencia seguirá creciendo en el futuro cercano (véase Jiménez y Perozo 1994; García Hierro et al. 1998; Chapin y Threlkeld 2001; Surrallés y García Hierro 2004; IIED 2006; Caballero y Zent 2006). Muchos proyectos de (auto)demarcación consisten de equipos compuestos por actores locales trabajando juntos con actores externos de los derechos de los primeros. Como tal, se enmarca en un patrón más generalizado en donde la relación tradicional de llevar a cabo proyectos de investigación con comunidades locales (indígenas, campesinas, etc.) se ha reposicionado radicalmente, moviéndose de un modelo unilateral donde se trata a las poblaciones locales como meros sujetos pasivos de investigación por parte de los actores externos hacia una nueva dinámica donde los miembros comunitarios se asumen a priori activos involucrados en proyectos más equitativos y colaborativos. En este escenario, los objetivos, métodos y epistemologías de investigación son producto de un diálogo de las partes desde el inicio. Típicamente, tal clase de investigación tiene una finalidad aplicada y dirigida a la resolución de un problema o necesidad en la vida real de los participantes. Pese a los beneficios de este tipo de colaboración es menester darse cuenta de las divergencias y choques interculturales potenciales que pueden surgir, no solo entre los mismos colaboradores sino entre ellos y otros actores (por ej., el estado en sus distintas manifestaciones). 
6 Apelamos a la auto-reflexión como componente importante de este proceso dialógico y colaborativo, y ofrecemos una narrativa sobre nuestra experiencia. Para organizar este discurso, delimitamos cuatro macro-tópicos:

- la importancia de las alianzas

- la ambigüedad del Estado

- la realidad múltiple del mapa

- la territorialidad como conservación biocultural.

\section{La importancia de las alianzas}

7 Entendemos el concepto de alianzas como la serie de actividades formales e informales que se establece entre dos o más partes que concurren en un mismo fin. En este caso, aquellas alianzas que se han articulado entre los indígenas y grupos, instituciones o individuos para apoyar el cumplimiento del derecho consuetudinario asociado al reconocimiento de sus tierras ancestrales. El proceso de llevar a cabo una autodemarcación es sumamente complejo y trabajoso, y en tal sentido requiere la unidad de esfuerzos de varias personas que aportan diferentes capacidades, habilidades y recursos a la mesa. Los Jodï y Eñepa saben mejor que nadie hasta donde se extiende, alcanza y termina su tierra, así como poseen un íntimo y extenso conocimiento de cada montaña, cada cañito, cada roca, cada mata de sus territorios. Esto es realmente asombroso desde edades muy tempranas incluso. Si se va de cacería con ellos, al perseguir un animal móvil es posible que den veinte y un vueltas pero el cazador o la cazadora siempre tiene la facultad de decir donde está su casa y con relación a qué está localizado. Es decir, nunca se pierden, es como si tuviesen una brújula digital en la cabeza. Pese al acucioso conocimiento biogeográfico de su territorio, los indígenas notaron que no sabían cómo hacer mapas al estilo occidental y por tanto requerían manejar y conocer las técnicas de cartografía científica. Debido a ello en el año 2001 los Jodï y Eñepa solicitan a los investigadores del IVIC su cooperación para mapear sus territorios. A nivel más profundo, podemos decir que no poseían las herramientas para comunicar su riqueza etnocartográfica al lenguaje de la sociedad occidental políticamente dominante. En ese sentido, los indígenas solicitaron una alianza formal con científicos con claros objetivos y roles para las dos partes. Aunque el personal del IVIC tienen entrenamiento formal en antropología y etnobiología respectivamente, y por ende no son geógrafos, ellos pudieron aprender y luego enseñar técnicas sencillas con las que pudieron construir mapas occidentales. Más allá de mapas mentales, con la ayuda del gps para registrar puntos (coordenadas precisas) y el manejo de programas de computación mediante los cuales se convierten esos datos en proyecciones gráficas geo-referenciadas, es totalmente factible producir mapas de alta calidad. Así que creemos que desde una perspectiva técnica, es necesario o por lo menos ventajoso contar con alianzas y la división de capacidades y labores al momento de llevar a cabo la demarcación.

Obviamente el proceso de reivindicación de los derechos territoriales no termina con la demarcación y en tal sentido hay otras alianzas que son de suma importancia, empezando con los contactos e intercambios de información con otros grupos indígenas que están en situación similar. Este tipo de intercambio está apenas comenzando en los últimos 4-5 años, entre los grupos indígenas Jodï y Eñepa, miembros de los cuales son co-autores de este trabajo, pero también a través de su participación en foros y encuentros tanto nacionales como internacionales por parte de representantes de las dos etnias. Jodï y 
Eñepa en ese sentido, se están articulando aunque sea de manera intermitente con redes de derechos humanos y territoriales de la Amazonía; han aparecido en el paisaje cultural con rostro individuado entre las culturas suramericanas. A ello se suma el que los investigadores comprometidos han contribuido activamente en hacer accesible información certera sobre las leyes, convenios, tratados nacionales e internacionales, que apuntan hacia la defensa de los derechos territoriales de los indígenas.

9 A nivel nacional, el establecimiento de contactos informales ha facilitado la toma de decisiones contextuales. Los Jodi de Kayamá por ejemplo y los Yekuana del Caura (otro grupo indígena que ha llevado a cabo un proceso de auto-demarcación de sus tierras), resolvieron juntos un conflicto potencial de solapamiento de los mapas/territorios a través de un acuerdo sobre un área compartida. Al hacer la solicitud formal para recibir la titulación o reconocimiento formal de sus derechos territoriales ya tenían un acuerdo sobre las áreas compartidas. En 2012, los representantes de la población Jodï en el Estado Amazonas sostuvieron negociaciones directas con sus contrapartes del grupo vecino, los Yabarana del Río Parucito, con el fin de dirimir posibles conflictos en las demarcaciones respectivas. Por su parte, los Eñepa de Kayamá, aunque constituyen una de las comunidades más aisladas y tradicionales de este grupo étnico, fueron los primeros de esa población étnica en construir una demarcación completa y sistemática de sus tierras comunitarias, y en tal sentido ha servido como inspiración y modelo para otras comunidades Eñepa a seguir. A partir de su experiencia en demarcación, los primeros establecieron contactos con la Asamblea del Pueblo E'ñepá, organización que agrupa varias comunidades y regiones, con sede en Caicara del Orinoco, para colaborar en un proceso más amplio de demarcación del territorio de todas las comunidades Eñepa del estado Bolívar. Así empezó una relación sostenida con esta organización, así como su participación en otras actividades de carácter pan-étnico, que ha persistido hasta la actualidad. Más allá de las relaciones establecidas con otros grupos indígenas, la gente de Kayamá también ha tenido contactos provisionales con algunos actores en la materia indigenista nacional. La más importante en el estado Bolívar (Kayamá) ha sido la visita del abogado Dr. Vladimir Aguilar Castro, profesor y miembro del Grupo de Trabajo sobre Asuntos Indígenas (GTAI) de la Universidad de los Andes (ULA), quien es especialista en el tema de los derechos territoriales de los pueblos indígenas. En Amazonas en cambio, los Jodï se han articulado con el abogado Dr. Luis Bello, miembro de la ONG Wataniba, quien les presta asesoramiento legal a diferentes grupos indígenas en su lucha por conquistar los derechos territoriales.

10 Durante todo el proceso de auto-demarcación, los Jodï y Eñepa recibieron ayudas de diferentes actores, de los sectores tanto público como privado, que merece mencionarse. En primer lugar, cabe destacar el apoyo moral y a veces logístico de los misioneros, tanto en Amazonas como en Bolívar, aunque estos últimos no jugaron un papel directo en la demarcación per se. El Instituto Geográfico de Venezuela «Simón Bolívar » (IGVSB) del entonces Ministerio del Ambiente brindó un taller en conceptos y métodos básicos de la Cartografía para los coordinadores durante una visita a Caracas en diciembre de 2001. Diferentes oficiales de los ministerios encargados con la rectoría del proceso de demarcación de tierras y hábitats indígenas (primero el Ministerio del Ambiente (2002-2004), luego el Ministerio del Poder Popular para los Pueblos Indígenas en el 2007) mostraron buena voluntad al tratar de avanzar los expedientes de los solicitantes, incluso más allá de su deber estrictamente institucional. Sin embargo, un problema ha sido el cambio de personal frecuente; típicamente los responsables de esta materia son personal 
contratado durante poco tiempo (menor a un año). Podemos decir que una vez que las autoridades militares recibieron la solicitud que los primeros autores elevaron a partir de la petición de las comunidades, autorizaron y ordenaron el traslado de oficiales de la Oficina Nacional de Identidad y Extranjería (ONIDEX) a Caño Iguana para efectuar la cedulación de la población de esa comunidad. ${ }^{4}$ Los militares cumplieron su deber cívico al facilitar la cedulación de los pueblos originarios del país, atendiendo el derecho a la identidad de estos indígenas que no contaban con cedulación anteriormente. En años recientes, diferentes activistas y organizaciones indigenistas (e.g. Organización de Pueblos Indígenas de Amazonas, Coordinadora de Organizaciones Indígenas de Amazonas) han denunciado que se ha paralizado el proceso de demarcación en el país (ver abajo), haciendo referencia particular al caso Jodï, entre otros, señalando que los problemas de la minería ilegal y la incursión por parte de grupos armados extranjeros está relacionado con esta situación de indefinición de la tenencia de tierras indígenas.

En resumen, los pueblos Jodï y Eñepa han contado con diversos aliados en diferentes momentos y para diferentes fines en su demarcación territorial y seguramente necesitarían otros más para poder avanzar en esta lucha. Recomendamos que otros grupos con intereses similares busquen aliados de diversos tipos para su causa.

\section{La ambigüedad estructural del Estado}

Durante todo el proceso de demarcación Jodï y Eñepa, antes y después, la posición y actuación del estado venezolano ha sido contradictoria y difícil de descifrar: a veces alienta y promueve, otras veces desalienta y obstaculiza. El proceso contemporáneo de demarcación y reivindicación de los reclamos históricos de los pueblos indígenas para que reconozcan sus derechos territoriales ha tenido como catalizador la constitución nacional del 1999 y la serie de leyes, decretos y reglamentos derivados de ella (véase arriba). Antes de esa fecha, con pocas excepciones el asunto de los derechos territoriales y humanos de las comunidades y pueblos indígenas no figuró como política de estado. Apenas un puñado de comunidades contaba con títulos otorgados durante el siglo xIX y en los años setenta y ochenta del siglo xx el Instituto de Agrario Nacional (IAN) había entregado unos 150 títulos, en su mayoría provisionales y no definitivos, sobre áreas pequeñas y fragmentadas que corresponden a comunidades individuales (véase Clarac 1983). Con el fin de convertir las nuevas leyes de la demarcación en realidad, el estado venezolano ha convocado comisiones ad honorem a niveles nacional y regional y según los informes o noticias publicitarias, a través de los Ministerios y las dependencias encargadas, ha destinado recursos y personal para avanzar con este propósito. También es cierto que ha otorgado títulos de propiedad a varias comunidades indígenas de diferentes etnias en diferentes estados. Por ejemplo, en marzo de 2013 el entonces Vice-Presidente Ejecutivo de la República, Jorge Arreaza, quien presidía la CNDHTI, anunció que entre 2005 y 2013 fueron entregados 80 títulos, beneficiando a las etnias Kariña (Anzoategui y Sucre), Kumanagoto (Anzoategui), Pumé (Apure), Mapoyo (Bolívar), Pemón (Bolívar) y Warao (Delta Amacuro), entre otros (véase VTV 2013). No se hizo nunca publico si estos títulos seguían los lineamientos prescritos por la ley de demarcación sobre el demarcación y autodemarcación comunitaria. Además de los títulos, durante este periodo el gobierno ha construido una cantidad considerable de viviendas en comunidades indígenas en el estado Amazonas y en otros distritos del territorio nacional. La entrega de títulos frecuentemente coinciden con fechas simbólicas (12 de Octubre, Día de la Resistencia 
Indígena) o campañas electorales (elecciones presidenciales de 2012 y 2013), visiblemente para maximizar su beneficio publicitario y político.

Por otra parte, existen distintas perspectivas más bien críticas de la gestión gubernamental en torno a la demarcación y titulación de tierras indígenas. Una de las críticas más contundentes es el ritmo muy lento y el poco alcance de los títulos entregados. Según un comunicado de la Coordinadora de Organizaciones Indígenas de la Amazonía Venezolana (COIAM) ${ }^{5}$, de fecha 4 de diciembre de 2014, la demarcación ha llegado a un sector muy reducido de la población indígena:

«Un estudio detallado del Proceso Nacional de Demarcación y sus resultados oficiales durante los últimos 15 años, evidencia que sólo se ha demarcado aproximadamente el $12,4 \%$ de los Hábitat y Tierras Indígenas, partiendo del número de comunidades censadas. En efecto, según información oficial existen en Venezuela aproximadamente unas 3101 comunidades indígenas (Ministerio de Pueblos Indígenas, 2007) y unas 2788 comunidades (Instituto Nacional de Estadística, Censo Indígena 2011), habiéndose entregado 80 títulos de demarcación en el período 2005-2013, más 06 anunciados en octubre de 2014, que benefician a un total de 372 comunidades, por un total aproximado de 2.841.518 hectáreas en el período 2005 - 2014... sólo se ha beneficiado a 11 pueblos indígenas (Kariña, Cumanagoto, Pumé, Jivi, Cuiva, Warao, Yukpa, Hoti, Pemón, Mapoyo, y Barí), de un total de 50 pueblos » (Censo Indígena 2011) (COIAM 2014).

14 Por otra parte, la mayoría de los títulos otorgados bajo la nueva ley cubren territorios relativamente pequeños, con referencia a comunidades individuales o agrupaciones de pocas comunidades y no a entidades colectivas como pueblos étnicos o poblaciones multiétnicas. Según las cifras citadas arriba (2.842.518 ha., 372 comunidades, 86 títulos), tenemos un promedio 7.638 ha. por comunidad. Como punto de comparación, observamos que la dotación acumulada de tierras por el desaparecido Instituto Agrario Nacional (IAN) en la llamada cuarta república consistía de 1.497 .615 ha. otorgadas a través de 154 títulos a 183 comunidades beneficiarios pertenecientes a 22 grupos étnicos, para un promedio de 8.184 ha. por comunidad (Caballero 2007). En este sentido, la nueva titularidad de tierras indígenas no luce muy diferente de la vieja titularidad auspiciada por el IAN, la cual fue severamente criticada en su época precisamente por el tamaño miserable de los espacios y la tendencia de fragmentar los territorios étnicos en islas de tierras con títulos comunitarios rodeados por extensiones mayores de las llamadas "tierras baldías".

Una excepción a este patrón de dar dotaciones "uni-comunitarias" y "pequeñas" fueron los títulos que se entregaron a los pueblos Yukpa y Barí en Diciembre de 2011, de 143.610 ha. y 325.570 ha. respectivamente. Sin embargo, esos títulos han sido fuertemente cuestionados porque al mismo tiempo reconocen los derechos de terceros (hacendados, parceleros, empresas madereras) asentados (legal o ilegalmente) en la zona antes del inicio del documento y de la potestad del Estado en autorizar la exploración y explotación de minerales o hidrocarburos en el subsuelo por parte de empresas extractivistas, por encima de los derechos de los habitantes originarios (Tillett 2012). También un abogado experto en la materia opina que el título Yukpa es « un documento vacío » ya que consiste en un formulismo jurídico que parece más un contrato privado, hace referencia a coordenadas geográficas de una manera desordenada y carece de soporte alguno al derecho sustantivo (Aguilera 2012). Como tal, algunos voceros de los mismos pueblos beneficiarios y sus defensores indigenistas han calificado esos títulos como «títulos chimbos » (Sociedad Homo et Natura 2012). 
16 El caso de la demarcación Yekuana-Sanemá es otro ejemplo que demuestra la renuencia del estado en reconocer los derechos indígenas sobre grandes extensiones. Antes de la Constitución de 1999, la organización indígena Kuyujani, agrupando un conjunto de comunidades Yekuana y Sanemá de la cuenca del Río Caura, junto con el Centro de Investigaciones Antropológicas de la Universidad Nacional Experimental de Guayana (CIAG-UNEG), realizaron la demarcación de una inmensa área de ese río, desde el bajo Río Nichare en el norte hasta la frontera con Brasil en el sur (Kuyujani 1998). Después de la promulgación de la nueva legislación, hicieron la solicitud de titulación de esta región de aproximadamente 4 millones de ha., siguiendo todas las normas y procedimientos establecidos. La solicitud pasó exitosamente por todas las instancias oficiales y fue aprobada por la CNDHTI el 10 de Octubre del 2006, en anticipación de la entrega pautada para coincidir con las celebraciones del 12-Octubre; solo faltaba la bendición presidencial. Sin embargo, el día siguiente el Presidente Hugo Chávez, decidió no aprobarla, aparentemente porque significaba la entrega de una extensión demasiado grande para una población demasiado pequeña y porque representaba un peligro para la unidad territorial y la soberanía nacional (Mansutti 2006). ${ }^{6}$ Esta historia demuestra los conflictos y choques de voluntad y actuación dentro del mismo gobierno. Algunas facciones o personalidades están en favor mientras que otras están en contra, y por eso parece que la marcha del Estado hacía la realización de los derechos territoriales de los pueblos indígenas procede con un paso adelante y otro paso atrás.

En el Estado Amazonas, el estado con mayor proporción de población indígena y con mayor extensión geográfica de ocupación indígena, hasta la fecha actual se ha reconocido la demarcación de un solo grupo: los Jodï de Caño Iguana. En 2012, se les entregó a representantes de esta comunidad un «certificado » en donde especifica que "otorga la propiedad colectiva" a dicha comunidad una superficie de 223.078 ha (Figura 5). La superficie indicada representa una reducción de $40 \%$ del área del mapa basado en la autodemarcación de este grupo, aunque no queda claro cuales áreas fueron borrados del mapa original ya que no hay especificaciones sobre coordenadas o linderos en este documento. No sabemos si existen otros documentos con información más precisa al respecto o si el título ha sido debidamente registrado tal como se especifica en la LOPI. Hemos averiguado con varias personas de esa misma comunidad y nadie ha indicado haber visto, leído o tener conocimiento de este título. El documento les fue entregado a dos Jodï en un acto público de campaña electoral en 2012. Según el testimonio directo de estos dos Jodï, luego de la toma de foto se les solicitó allí mismo que devolvieran el documento pues debía ser registrado y fue la última vez que lo vieron. En síntesis, la existencia real de un documento legal o título de propiedad territorial de las tierras Jodï en Amazonas no ha podido verificarse. En todo caso, asumiendo que lo antes mencionado constituye el único título legítimo en el estado, queda pendiente la tarea de demarcar o legalizar las tierras de los otros grupos indígenas. Actualmente, hay por lo menos cinco expedientes abiertos esperando una decisión y existen muchos grupos y comunidades amazónicos más para los cuales ni siquiera se han abierto expedientes ${ }^{7}$. La razón de por qué no hay más expedientes se atribuye a la falta de información adecuada o de recursos para llevar a cabo la documentación necesaria. COIAM concluye que los pocos avances en esta materia

« evidencian una cierta falta de voluntad política con relación al desarrollo del proceso de demarcación y no se corresponden con la naturaleza amplia y garantista de los preceptos constitucionales que desarrollan los derechos de los pueblos indígenas en Venezuela »(COIAM 2014). 
Figura 5: Certificado de Título de Propiedad, Jodï de Caño Iguana

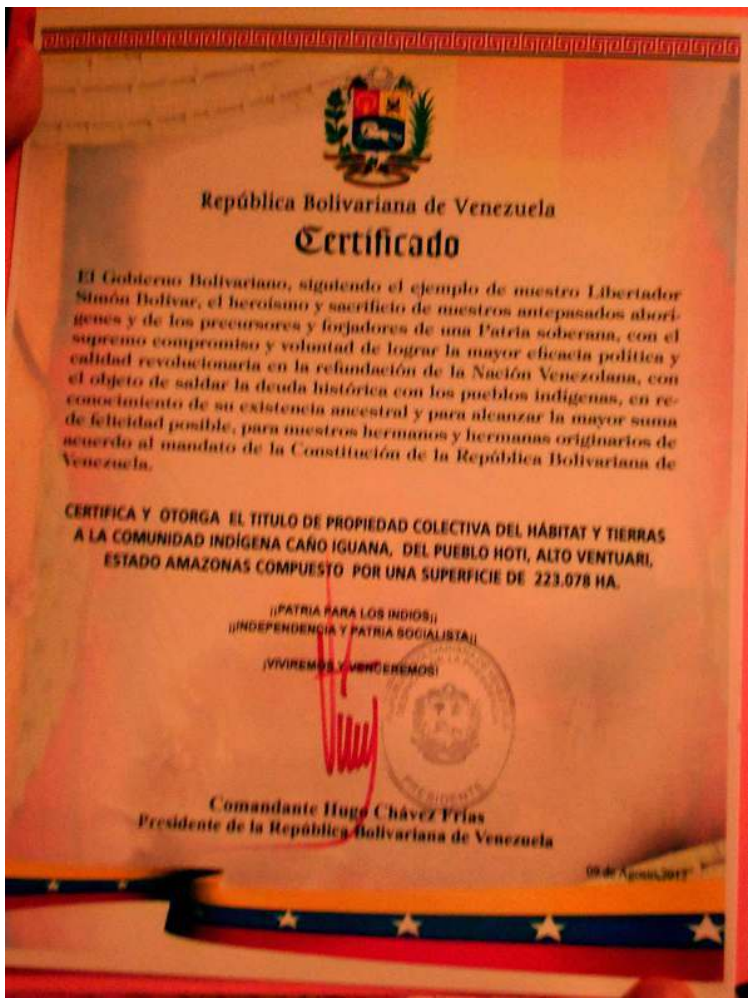

CRÉDIT : S \& E. ZENT

En resumen, después de más de 15 años bajo el régimen legal bolivariano, la gran mayoría de los grupos indígenas - incluso grupos que han participado muy activamente en el proceso de demarcación - siguen sin tener ningún título o aval tangible para demostrar legal y contundentemente sin ambigüedad alguna que son los dueños verdaderos de sus tierras originales o ancestrales. Pese al evidente objetivo reivindicativo (es decir, justicia social para los más desposeídos) de la legislación actual, es necesario evaluar por qué no han habido mayores resultados hasta ahora. Sin duda una de las causas ha sido la poca o nula funcionalidad de la estructura administrativa establecida para llevar a cabo el proceso de demarcación.

Inicialmente (del 2001 hasta 2011), se designó como la entidad ejecutora o Secretaría Ejecutiva-Administrativa oficial del proceso de demarcación de hábitats y tierras indígenas al Ministerio del Ambiente a través de la Dirección de Planificación y Ordenamiento Ambiental (POA), aunque los pueblos indígenas nunca habían sido su prioridad ni parte de su área de competencia. Retrospectivamente, es evidente que POA nunca prestó la atención necesaria y nunca logró dar el impulso adecuado. Por otra parte, a finales de 2001 el Ejecutivo nombró una Comisión Nacional de Demarcación de Tierras y Hábitats Indígenas (CNDTHI) compuesta al inicio paritariamente por representantes de ocho ministerios públicos y ocho representantes indígenas. Se estipuló que la CNDTHI tendría sede en Caracas, y dos años después de su instalación crearon las comisiones regionales con sede en las capitales de los ocho estados con población indígena. Tanto la comisión nacional como las regionales están encargadas de promover y supervisar los procesos locales de demarcación. Sin embargo, después de una fase inicial - relativamente corta - de mayor actividad, las comisiones casi dejaron de funcionar y en la opinión de 
diferentes observadores y representantes indígenas el proceso se encontró básicamente paralizado por varios años. La capacidad de actuar de las comisiones nacional y regionales siempre fue limitada debido al carácter ad honorem de sus miembros y la carencia de presupuesto independiente, incluso para facilitar el traslado de los representantes indígenas oficiales que eran parte de la Comisión para asistir a las sesiones de la misma. Otra limitante puede haber sido la composición heterogénea de la CNDTHI, consistiendo de representantes de diversos ministerios o instituciones públicas con distintos intereses, además de los representantes indígenas que provienen de diferentes regiones, algunas veces alejadas y de difícil acceso o transporte hasta las zonas urbanas. Más allá del problema de ponerse de acuerdo en los asuntos tratados, el simple hecho de lograr el quorum en las reuniones de la comisión se ha convertido en un desafío formidable debido a la falta de recursos propios. No debemos subestimar las limitaciones o carencias económicas en otros niveles también. Pese a que por ley el estado tiene que financiar el proceso de demarcación, es muy difícil acceder a este tipo de apoyo. En el caso de los Jodï y Eñepa por ejemplo, nunca recibieron ningún tipo de apoyo económico para realizar el trabajo (más allá de lo aportado por el IVIC). Aunque por ley se designó al Ministerio del Ambiente la responsabilidad económica de llevar adelante el trabajo de demarcación, cuando solicitamos al IGVSB facilitar los mapas de base o imágenes cartográficas de la zona que Jodï y Eñepa necesitaban para preparar los mapas, fueron negados pese a que trataron de negociarse bien sea a través de descuento, mediante un convenio o intercambio de datos que favorecieran ambas partes, los mapas requeridos por parte de ellos en tanto que los dos primeros autores proporcionaron georeferenciación en terreno y toponimia de las áreas demarcadas. Otro des-estímulo ha sido de índole burocrático. Los requisitos para cumplir con la apertura del expediente no son solo muy complicados sino peor todavía, parece que siempre van cambiando. Aunque es muy común encontrar oficiales o personeros de las instituciones gubernamentales con mucha sensibilidad y deseos de ayudar para avanzar con la aprobación de los expedientes, dos factores limitan significativamente tal apoyo: la carencia de recursos materiales y la muy frecuente rotación de personal dificulta la continuidad del proceso.

En 2010, una marcha de indígenas y actores diversos (defensores de derechos humanos, líderes comunitarios, académicos, etc.) que han acompañado las dinámicas de luchas de derechos territoriales indígenas apoyaron al hermano jesuita José María Korta quien realizó una huelga de hambre para protestar la falta de progreso en la demarcación de tierras indígenas, así como otras violaciones de los derechos humanos de los pueblos indígenas en Venezuela (Véase: http://venezuela.indymedia.org/pt/2010/10/27797.shtml ). Esta acción, acompañada por una serie de manifestaciones asociadas, generó una racha de publicidad negativa y convenció al gobierno emprender algunas reformas en el marco legal y la administración del proceso de demarcación (Véase: Decreto Nro. 7.855 publicado en Gaceta Oficial № 39.624.). La más importante fue sustituir al Ministerio del Ambiente como rector principal del proceso de demarcación a favor del recién creado Ministerio del Poder Popular para los Pueblos Indígenas (MPPPI).

21 Paradójicamente, el nombramiento de éste último como el nuevo rector fue acogido con consternación por muchos sectores indígenas tanto organizados como individuales que percibían que el MPPPI no apoyaba sus luchas territoriales ni escuchaba su clamor favoreciendo en cambio aquellos oficiales u gubernamentales. Es así que dicho nombramiento desencadenó pronunciamientos de inconformidad por parte de varias organizaciones indígenas. Entre las razones mencionadas por su rechazo, notamos: la 
falta de consulta previa y participación de los pueblos y comunidades indígenas en la toma de esta decisión; y desconfianza en la capacidad de la ministra titular del MPPPI, quien ahora se convierte en la máxima autoridad del asunto de demarcación territorial, para dirigir dicho proceso de una manera adecuada. La gestión de la ministra fue criticada severamente porque

« no haya logrado construir los consensos necesarios y la participación para materializar la implementación de los derechos indígenas y se haya dedicado a promover la división, el enfrentamiento y la deslegitimación de los pueblos indígenas y sus organizaciones » (ORPIA et al. 18.03.11).

Además, objetaron que la reestructuración "limita la participación directa ", debido a que se cambió la representación indígena en la CNDTHI de la figura de « representantes indígenas ", con voz y voto, a simples "voceros", sin voto (Tillett 2012). Otro cambio significativo es que ahora los representantes indígenas en la CNDTHI son elegidos por el MPPPI.

La intensidad de las protestas impulsó como respuesta del ejecutivo a cambiar temporalmente el ente ejecutor de la demarcación en la figura de la Vice-Presidencia. Fue entonces cuando hacía finales de 2011 se decide cambiar la normativa legal otra vez y anuncian un plan ambicioso para lograr la demarcación y titulación de una cantidad de tierras indígenas en diferentes estados del país antes de terminar el mes de agosto de 2012. El rol del MPPPI a la cabeza del proceso de demarcación se ratifica y asume la responsabilidad de cumplir el cronograma de potenciales tierras tituladas. Al percatarse del nuevo plan, un observador astuto preguntó retóricamente: « ¿cómo pretenden lograr en 12 meses lo que no han podido hacer en 12 años?» (Aguilera 2012). En todo caso, durante varios meses del año 2012, por cierto año de elección presidencial, hubo una notable alza en los movimientos y actividades de funcionarios públicos dirigidos a verificar y completar los datos y avanzar los expedientes abiertos. Sin embargo, en el estado Amazonas, como ya se mencionó, se logró aprobar solo la demarcación Jodï. En Marzo de 2013, pocas semanas antes de la elección presidencial de ese año, hubo una ceremonia de entrega de títulos televisada en el estado Amazonas pero, curiosamente, ninguno de los recipientes fueron de Amazonas.

A pesar de la renovación de esfuerzos para llevar adelante la demarcación más recientemente, podemos detectar algunos de los mismos problemas de antes: escasez de recursos económicos o logísticos para apoyar a los grupos locales en sus actividades de auto-demarcación o para llevar a cabo los viajes de evaluación o verificación por parte de las comisiones; conflictos entre diferentes actores que forman parte de la comisión regional; una cantidad de requisitos que, al parecer, no tiene relación muy clara con la demarcación per se; carencias de organización, información y comunicación por parte de los funcionarios del MPPPI encargados con manejar el nuevo proceso, etc.

Si fuésemos cínicos podríamos resumir esta situación con la observación de que en papel Venezuela tiene las políticas más avanzadas y amplias de América Latina en materia de los derechos territoriales de los pueblos indígenas mientras que en la tierra o la realidad material es uno de los más atrasados, incluso en comparación con su vecino inmediato de Colombia donde los los resguardos indígenas abarcan un total de 31.207.978 de hectáreas tituladas (COIAM 2014 y véase también Silva 2012). Pero preferimos ser optimista y creer que son inconvenientes temporales que pueden superarse con más voluntad y mejor administración del proceso por parte de las autoridades. En todo caso, creemos que las organizaciones indígenas y sus aliados deberían tener esto muy claro: su 
benefactor es y probablemente siempre será ambiguo al momento de reconocer sus derechos. Por lo tanto, los indígenas deben asumir una posición protagonista y activista, insistiendo en el cumplimiento de los compromisos y promesas hechos por el estado y llevando a cabo el mapeo de territorios y compilación de documentos asociados de una manera independiente aunque apoyado por sus aliados.

\section{La realidad múltiple del mapa}

Aunque nuestra meta en este proyecto era originalmente producir un mapa definitivo de las tierras Jodï y Eñepa, nos dimos cuenta muy temprano en el proceso de su elaboración, de que el mapa es un medio muy limitado para representar la compleja y dinámica relación que tienen los indígenas con el paisaje. Desde el inicio de esta actividad se hizo evidente que las nociones espacio-temporales de los Jodï y los Eñepa no solo eran múltiples sino en algunos sentidos incompatibles con aquellas nociones cartográficas occidentales codificadas por coordenadas numéricas estáticas y fijas. El espacio indígena puede ser oral, simbólico, incorporado, morado, repleto de dinámicas y cambios. En una palabra vivido. En ello conjugan diversas temporalidades que resulta imposible representar en un mapa métrico bi-dimensional convencional.

Para los Jodï y Eñepa que participaron en este proyecto, la tierra está inserta en una noción de continuidad pragmática e ideológica de las esferas cósmicas y sociales. Es utópica la definición de tierra/naturaleza como a-parte de lo humano/sociocultural porque todo lo vivo es potencialmente social. Las nociones tradicionales occidentales asumen una separación entre espacio natural y espacio cultural que contradice lo afirmado por Jodï y Eñepa quienes enfatizan la unidad y pertenencia a la vida, la ecogonía-cósmica de compartir y la ontología de morar, habitar, estar inmerso, compenetrar(se) con el entorno: ser el cosmos holísticamente. Jodï y Eñepa tienen su dínamo en el territorio (en físico, dinámico vital) no en el mapa (en papel, estático representado).

En este sentido, mitos y conductas actuales cotidianas de caza-pesca-recolección sustentan en la praxis la visión de que el mundo no es solo ocupado estáticamente, sino habitado y modificado, reproducido y recreado, cambiable y también cambiante pues está en flujo y movimiento permanente. Jodï y Eñepa extienden responsabilidades de vida a todo lo que existe: el objetivo humano fundamental es seguir reproduciendo la interconexión de los seres como única estrategia posible para mantener la existencia del mundo. Tal responsabilidad cosmogónica es la marca por excelencia de la humanidad. Igualmente, pescar, recolectar, cocinar, beber, cazar, etc. son parte de un intercambio continuo vital. Así como se escucha en los mitos recurrentemente, la generación de la vida es circular: no parece haber discontinuidad lineal temporal absoluta ni espacios estáticos, pues el tiempo mismo es espacializado. Pese a que no pretendemos extendernos en las polisémicas nociones de tiempo entre los Jodï y Eñepa damos un breve ejemplo acá asociado a los resultados de la elaboración de los mapas. En el mapa Eñepa, se pueden observar diferentes topónimos que hacen referencia a eventos y hechos del dios creador Mareoka durante un tiempo primordial tales como el caño Yakakun, que hace referencia al color oscuro de las aguas que son producto de que el dios lavó su primer curare en ese caño siendo éste de color negro. También en las zonas donde se encuentran muchos individuos de una especie botánica se dice que es justamente el lugar donde se creó la planta originalmente. Más allá de los marcadores en el espacio de los tiempos de origen, 
en el espacio actual se gestan y reproducen conductas que fueron pautadas desde el amanecer del tiempo y su exitoso resultado deviene de ello. Así que la continuidad, o más bien el contrapunteo, entre pasado y presente se manifiesta no solamente en las huellas de impacto ambiental visibles en los paisajes contemporáneos sino también en la praxis de la vida cotidiana. Es evidente que una noción compleja del espacio como ésta no comulga ni puede representarse en un mapa cartesiano, es por ello que la representación espacial puede ser nada más que un dibujo si los símbolos e íconos se descontextualizan pero al contrario pasan a reificar y ser la vida misma si éstos se incorporan y reconocen como dinámicos en los mapas mismos. Vale añadir que por decisión de las comunidades, algunos elementos registrados (coordenadas) y representados (símbolos e íconos) en los mapas iniciales se suprimieron del mapa final pues se consideraron importantes para su historia y devenir pero no para la solicitud legal de sus tierras. Adicionalmente, otras coordenadas y elementos se codificaron solo para la comprensión de cada grupo étnico y no para el observador externo.

Al intentar traducir el complejo mapa indígena (en físico y en vivo) a una imagen estática, icónica, escrita en papel o grabado en forma digital, nos dimos cuenta que estamos cometiendo una grave distorsión que puede tener implicaciones prácticas además de las obvias imprecisiones académicas. El mapa escrito tiene permanencia y en tal sentido da la ilusión de un territorio fijo, un pueblo fijo, una cultura fija, una historia fija, un futuro fijo, aunque sabemos que la realidad es otra. Por lo tanto, abogamos que el mapa sea leído y entendido como un documento parcial, temporal y aproximado de la territorialidad indígena, cuya forma y contenido son hasta cierto punto determinados por el criterio de territorialidad desde una perspectiva occidental y dirigidos al cumplimiento de un requisito legal.

30 A pesar de las grandes diferencias señaladas entre la cartografía occidental y la indígena, esto no significa que los pueblos indígenas no sean capaces de hacer mapas al estilo cartesiano o usarlos para comunicar sus derechos territoriales. Ni los Jodï ni los Eñepa tuvieron ningún problema en adoptar, o más bien, en apropiarse de la tecnología y del medio del mapa. Estaban conscientes y claros de que necesitaban mapas para defender su espacio: el mapa constituye un instrumento legal de poder para alcanzar en términos legales derechos y control sobre la tierra, aunque implica la reducción o simplificación de las complejas nociones indígenas sobre el territorio. El mapa geo-referenciado está legitimado dentro de un sistema político ajeno al indígena, y no debe sorprender la receptividad de los indígenas a esta nueva forma de representación porque al negociar sus derechos ante el estado es este sistema justamente su arena de acción. Esto es precisamente lo que analistas como Arturo Escobar llaman conocimientos híbridos (Escobar 1995; pero véase también Pérez Ruíz 2016). En este contexto, es interesante notar que cuando entregamos uno de los expedientes, las autoridades a nivel regional cuestionaron la legitimidad del mapa porque era demasiado profesional, decían, y dudaron que ello pudiera haber sido producido por indígenas. Insistieron en que esperaban recibir los llamados mapas mentales dibujados a mano. ¿Nunca se les ocurrió que un dibujo en papel con lápices o creyones a color puede ser tan ajeno de la realidad indígena como un mapa digital y geo-referenciado?

31 En realidad los Jodï y los Eñepa elaboraron tanto un mapa dibujado a mano como uno producido por medio de un programa de computadora SIG. En el caso del primero, resultó un trabajo en cual se incorporaron múltiples y variadas manos (y mentes). En el papel quedaron representados los ríos principales, montañas, lagunas, sitios de importancia 
mitológica-histórica, una fracción de la toponimia en lengua local, dibujos de varias especies de flora y fauna, lugares asociados a su historia remota o reciente, migraciones, hitos culturales, etc. El mapa dibujado de los Jodï de la región sur (Amazonas) era especialmente notable, no menos por la riqueza de elementos sino por la orientación multi-direccional. Es decir, no hubo lo que podemos identificar como un lado arriba y otro abajo, ni una margen izquierda y otra derecha, por lo tanto no hubo una sola dirección u orientación desde la cual uno podía visualizar la imagen. Por otro lado, el mapa computarizado se creó con el programa Arc-View 3.3 y se imprimió utilizando un plotter del Departamento de Fotografía Científica del IVIC. Dicho mapa está debidamente geo-referenciado según latitud y longitud y la ubicación y trayectoria de los elementos de base, tales como ríos, curvas de nivel, línea divisora estatal y capas de vegetación fueron tomados de fuentes cartográficas oficiales o científicas. Superimpuestos sobre esta base están los elementos culturales o etno-cartográficos. Estos incluyen la toponimia, la cual, como en el otro mapa, está escrita en el idioma indígena (Jodï o Eñepa) utilizando alfabetos que son propios de esas comunidades y que fueron desarrollados a través de un proceso de consulta consensual dentro del marco de este mismo proyecto ${ }^{8}$. La toponimia representa uno de los aspectos más novedoso del mapa en el sentido del gran número de nombres que aparecen - aunque constituyen una fracción del total que saben - en comparación con la carencia - o casi ausencia total - de nombres que corresponden a esta zona en los mapas oficiales. Además de la toponimia, hay una serie de elementos que son representados por medio de iconos. Los iconos fueron creados en base de dibujos realizados por miembros de las mismas comunidades participantes aunque en algunos casos fue necesario modificarlos para resaltar su distintividad simbólica. Los iconos pueden agruparse en 7 clases básicas: viviendas, conucos, caminos, rasgos hidrográficos, rasgos topográficos y comunidades biológicas y sitios sagrados. Dentro de cada categoría, se incluyen muchas más sub-categorías. Especialmente numerosa y variada son los iconos que corresponden a especies naturales dominantes o indicadores de ciertos lugares. Aunque la tecnología digital no es indígena, obviamente, el método empleado para recabar los datos que se ingresaron en el programa sí fueron: muchos Jodï y Eñepa recorrieron grandes extensiones de sus territorios respectivos para registrar con gps todos los sitios marcados en los mapas. Sin la intervención de sus socios externos, los indígenas se organizaron en grupos de colectores de datos por categorías y sectores lo cual resultó la incorporación de ancianos, mujeres, adolescentes y niños muy variada, amén de la rectoría de adultos líderes particulares. Algunas de las expediciones duraron varios días, semanas e incluso meses, y los equipos tuvieron que sobrevivir con los recursos silvestres de cacería o colección que encontraron durante el viaje. En este sentido, podemos calificar a los mapas geo-referenciados como experimentados, vividos además de ser mentales, abstractos. Es decir, son productos de una auténtica experiencia indígena de caminar a lo largo y ancho de su territorio, de trepar las montañas y atravesar los ríos, de acampar en diversos lugares durante sus viajes, de extraer comida y otros recursos del ambiente selvático y de entrar en contacto con la multitud de seres materiales y espirituales que habitan en esos lugares.

32 También lo más importante del proceso de demarcación no ha sido necesariamente la producción del mapa ni la solicitud formal ante el estado sino la concientización en ellos de defender la tierra y su acceso a ella. Al comenzar el proyecto de auto-demarcación con las comunidades, preguntamos a varias personas locales su opinión sobre el proyecto y el trabajo que íbamos levantar. En general, la respuesta de los interrogados subrayaba la importancia de la tierra para la vida de ellos mismos, sus hijos y las generaciones por 
venir, por ello no dudaban en apoyar y cooperar con el proyecto comunitario. No percibimos indicaciones explícitas de que los indígenas sentían amenazas por parte de otros grupos foráneos hacia sus tierras, antes bien, sus expresiones sobre los derechos a la tierra enfatizaban más la inclusión en el acceso de todos ellos y menos la exclusión en el acceso de otra gente. Por contraste, su discurso sobre la tierra ha cambiado en los últimos años. Son mucho más conscientes de las ambiciones de los terceros y la necesidad de definir límites como medida de protección. Los Jodï y Eñepa de Kayamá han señalado a la demarcación como norma para regular la ocupación, tránsito y uso de la tierra entre ellos mismos. En algún momento nosotros sugerimos que podían designar un área común, donde los dos grupos pueden tener acceso de uso y disfrute libre, pero ellos rechazaron la idea y dijeron preferir fronteras claras y exclusivas entre los dos grupos. Los Jodï de Amazonas han experimentado las incursiones de mineros en los últimos años e invocan a la demarcación como evidencia de su derecho de vivir libres de esta amenaza. También ellos están actualmente en proceso de negociación de linderos territoriales con grupos vecinos como los Yabarana y los Yekuana. Su posición al respecto se ha fortalecido durante los últimos años (especialmente en comparación con el 2006 cuando hubo una ronda inicial de discusión con los Yabarana) y hacen referencia al mapa, o más bien a los caminos que transitaron durante el proceso de auto-demarcación, para defender su posición.

\section{La territorialidad indígena como conservación biocultural}

Como académicos, cuyo tema de investigación trascendental consiste en estudiar y entender la relación entre los grupos humanos y su medio ambiente, uno de los aspectos más estimulantes de participar en un proyecto de auto-demarcación territorial desde un punto de vista intelectual era la oportunidad de aprehender cómo los mismos grupos locales conciben y proyectan esta relación en el espacio (y el tiempo) a través de la producción de mapas y otros materiales etno-cartográficos. Aunque los investigadores del IVIC habían llevado a cabo un estudio etnobiológico de los Jodï previamente, no habían prestado suficiente atención a la dimensión espacial de sus conocimientos y conductos etnobiológicos. La etnocartografía nos abre una ventana estratégica para visualizar a escala del paisaje humano la interdependencia o causación mutua de los fenómenos culturales y los naturales: por un lado, la construcción del paisaje a partir de nombres, significados y actividades impuestos por el sistema cultural y por otro lado, la influencia y penetración en la vida social-simbólica-espiritual de la sociedad humana por parte de las plantas, animales, suelos, ríos, montañas y otros rasgos naturales de un contexto ambiental particular.

Uno de los resultados más impresionantes de la colecta de datos fue la preponderancia y diversidad de especies biológicas como elementos distintivos y constitutivos del paisaje cultural. La categoría de especies o grupos biológicos resultó la más numerosa en términos de elementos seleccionados por los mismos indígenas para el registro de coordenadas y del significado cultural asociado con el sitio. De 3399 topónimos registrados por los Jodï de Kayamá, por ejemplo, 1897 (56\%) tenía un referente botánico o zoológico. Esto incluye 169 etno-taxa de plantas y 80 etnotaxa de animales (Zent, Zent y Quatra 2010). Pero quizás más importante que la frecuencia de mención o diversidad de especies fue la distribución espacial de estos elementos. Los indígenas reconocen una 
gran cantidad de biotopos o tipos de bosque marcados por la presencia o dominancia de ciertas especies salientes o indicadoras. Estos lugares se nombran típicamente a través de expresiones binomiales en donde el primer lexema se refiere al nombre de la especie o clase de especies indicadora y el segundo lexema se refiere al término genérico para el ecotopo o comunidad biótica (por ej., en Jodï: bade jkyo «bosque de seje ", Oenocarpus vacaba; ulu jwï « cerro de cucurito » Attalea maripa; en Eñepa: kachama patan « espacio de pijiguao »). En algunos casos, la distribución de tipos de bosque es muy específica, peculiar y altamente localizada o concentrada en una zona delimitada (como es el caso de los bambúes con que fabrican la cerbatana y la flauta grande). En otros casos, la fito o zoogeografía puede ser muy recurrente y espacialmente extendida (como es el denominado «barro del danto»). En este sentido, la compilación de datos etno-cartográficos y su proyección geográfica nos dio una idea de la distribución bastante variable o irregular ( patchy) de muchas de las especies de las cuales los Jodi y Eñepa dependen para producir y reproducir su acostumbrado modo de vida. Esto significa también el movimiento de personas en el espacio para acceder a los variados recursos naturales, y por lo tanto la necesidad de tener un territorio amplio a su alcance. Cabe destacar que muchos de esos biotopos (o ecotopos) no han sido reconocidos en mapas o clasificaciones científicas (por ejemplo, los mapas fito-geográficos), por lo cual podemos inferir que solamente los indígenas tienen conocimiento de esto por ahora. En definitiva, los mapas culturales de territorios indígenas también resultan en cierta manera en mapas de la biodiversidad de esta región e incluso pueden ser la base de mapas de manejo de recursos.

Esta última observación nos hace reflexionar sobre la conexión importante entre conocimiento tradicional o local, biodiversidad y territorio. La localidad, o el vínculo esencial con un lugar particular y delimitado ha sido señalada como una de las características esenciales o diagnósticas del conocimiento ambiental tradicional, también conocido como TEK (siglas para «traditional environmental knowledge») (Véase: Nazarea 1999; Ellen y Harris 2000). Esto no quiere decir que está completamente aislado de influencias y transmisiones externas, pero en todo caso es la integración e interpretación propia, según los significados, valores y propósitos de la gente local, que explica su alteridad o singularidad. A través del TEK, el ambiente natural ejerce un impacto significativo sobre diferentes aspectos culturales, tales como patrón de asentamiento, sistema de parentesco, socialización de jóvenes, conductas rituales, creencias religiosas, mitología, etc. (Zent 2009). En cambio, ha sido ampliamente demostrado que el TEK puede tener un papel importante para el uso sostenible de los recursos naturales y, por ende, la conservación de la biodiversidad (lo cual es distinto del uso de TEK para el aprovechamiento de la biodiversidad) (Véase por ejemplo Posey 1999). En algunos casos, se ha demostrado que pequeños grupos humanos no industrializados han alterado a sus ambientes a través de su tecnología tradicional en pro de la biodiversidad (Zent y Zent 2004). Considerando su valor ecológico, diversos actores investigadores científicos, conservacionistas, responsables de formular políticas ambientales, activistas sociales y organizaciones indígenas - han promovido la preservación y fortalecimiento de los conocimientos y prácticas tradicionales de producción y manejo de recursos. En vista del enlace fundamental entre el plano cultural y el plano biológico se ha propuesto que las políticas y programas de conservación ambiental deberían basarse en un modelo integral de conservación biocultural en donde se busca proteger tanto las culturas endémicas tradicionales como las especies y ecosistemas naturales (Carlson \& Maffi 2004). 
36 Nuestro argumento es que la seguridad territorial es igualmente importante para la llamada conservación biocultural. Coincidimos con Hunn (1999) al considerar que las prácticas cotidianas o frecuentes de actividades de subsistencia son cruciales para la transmisión y preservación del conocimiento correspondiente, y para poder realizar dichas actividades es necesario contar con la tierra adecuada, la cual traduce en acceso a los recursos sobre los cuales depende la subsistencia. ${ }^{9}$ Dado el carácter culturalmente diferenciado de la población indígena, el reconocimiento de sus derechos territoriales puede hacer una contribución notable a la preservación de sistemas de TEK endémicos y, en consecuencia, el buen manejo y conservación de la biodiversidad en estos lugares. La defensa de los derechos sobre la tierra como estrategia de conservación ha sido implícitamente reconocida por el Convenio sobre la Diversidad Biológica (CDB). En la conferencia de las partes en el año 2010 (CBD-COP 10), adoptaron la figura de « Tasas de Seguridad Territorial » como indicador focal del Plan Estratégico 2020. Esto porque se considera que esta variable está directamente asociada con conocimientos, prácticas e innovaciones tradicionales que contribuyen a la conservación de la biodiversidad (artículo 8j del convenio). Sugerimos que este reconocimiento de facto de la integralidad de la seguridad territorial, o los derechos sobre la tierra, para la conservación biocultural debería extenderse y ser adoptado como política oficial de las naciones miembros del convenio en los tratos con sus poblaciones indígenas. Más allá de la cuestión moral - la justicia social implícita en la reivindicación del derecho de poblaciones desposeídas - no debemos perder de vista los beneficios ecológicos de reconocer la territorialidad indígena. Se requiere entonces la amplificación del concepto de conservación biocultural al tomar en cuenta el criterio geopolítico, en otras palabras, buscamos un modelo de conservación geobiocultural.

\section{Conclusiones}

37 La investigación etnoecológica se ha ocupado tradicionalmente de la indagación básica de los conocimientos y habilidades culturalmente específicos de una población local y la traducción o interpretación de este esquema conceptual según el lenguaje y categorías del paradigma científico. Hoy en día, sin embargo, la etnoecología se ha convertida en una sub-disciplina más práctica y aplicada, con aplicaciones importantes en el desarrollo de tecnología apropiada, manejo sustentable de recursos, conservación biocultural, evaluación de impactos ambientales y otras. Este viraje de propósito está directamente relacionado con cambios importantes en la apreciación y valorización de los conocimientos ambientales locales por parte de la sociedad global. Gracias en parte a la publicación de los resultados de investigaciones etnoecológicas rigorosas, se han dado cuenta de la amplitud y profundidad de conocimientos ambientales que poseen muchos grupos indígenas y campesinos. Más precisamente, se reconocen a las sabidurías locales como incorporadas en el tejido individual y social, las cuales se perciben en el día-a-día en prácticas y conductas que reafirman un estilo de vida sustentado en finos conocimientos de la flora, la fauna, interacciones entre especies, los suelos, los aguas, el clima, las comunidades ecológicas y otros componentes ambientales. Tales cuerpos de conocimiento han ido incrementando su posicionamiento nacional e internacional, en contextos académicos, políticos y culturales hasta en medios masivos de comunicación (prensa, cine, televisión, internet, etc.) al punto de considerarse no como conocimientos inferiores, sino como epistemologías alternativas. La tesis de paridad epistemológica ha 
ido retroalimentando al campo de investigación etnoecológica en el sentido de que recientemente se está haciendo mayor esfuerzo por enfatizar interacciones interculturales autónomas colaborativa y consensuada de contenido, objetivo y fines (Pérez Ruíz 2016).

Los proyectos de demarcación territorial y mapeo comunitario representan precisamente una rama dinámica de investigación etnoecológica con una vocación activista que depende de la colaboración efectiva entre científicos y actores locales. Esto implica un cambio en la relación que se establece entre el investigador foráneo entrenado en el método científico y el colaborador nativo quien posee conocimiento experto de la etnociencia local. Según el modelo clásico de investigación, el académico llega al campo armado con un cuerpo de teorías, métodos y problemas de investigación, pero este bagaje no siempre tiene relevancia para los intereses o necesidades de la población de estudio. En el contexto de la investigación colaborativa, como lo es un proyecto de autodemarcación, la relación de trabajo entre el científico y el etnocientífico resulta más abierto, interactivo y participativo, y el método empleado es menos un ejercicio de observación y análisis sistemático y más como un diálogo entre saberes. En algunos casos, como el nuestro, la relación tradicional entre el científico y el nativo se invierte, en tanto que los primeros sirven como fuentes de información estratégica y los segundos son los responsables del diseño de investigación y de la colección y análisis de datos. Para ser efectivo en este rol, el investigador tiene que desarrollar capacidades que normalmente no se le enseñan en la academia, especialmente como articularse con actores e instituciones no-académicos, no solamente a nivel local sino también con autoridades gubernamentales (tanto regional como nacional), organizaciones indigenistas o activistas, fuentes de financiamiento, etc. Los participantes locales por su parte deben dedicarse a aprender bien nuevas tecnologías, como en el caso presente el uso de gps y computadoras y la alfabetización en la lengua local, y persistir con el trabajo y la promoción de su causa aunque los resultados deseados lucen distantes. También queremos destacar que esta modalidad de investigación puede ser sumamente enriquecedora desde un punto de vista estrictamente académico en el sentido que los académicos, bajo la dirección conductora de sus colegas locales, llegan a descubrimientos o entendimientos no anticipados, como en este caso con la asociación de la toponimia Jodï, la conceptualización de biotopos y la biogeografía irregular (patchy) de especies. En conclusión, queremos afirmar que los etnoecólogos académicos poseen tecnologías intelectuales y materiales con que podrían hacer contribuciones importantes para el avance de los derechos de los pueblos indígenas $\mathrm{y}$ otros fines de justicia socioambiental, $\mathrm{y}$ al mismo tiempo las experiencias de colaboración con las comunidades locales ofrecen ejemplos y pautas para el desarrollo académico de la investigación etnoecológica.

Finalmente es menester subrayar las dinámicas de aprendizaje bidireccional subsumidas en este tipo de proyectos referidas por una parte a la conciencia de que las construcciones de conocimientos diferentes asociados a la tierra (cómo, cuándo, quienes y por qué) provienen de diversas fuentes y tanto los académicos como los indígenas aprenden y aprehenden en el proceso de la realización de mapeos comunitarios y por otra parte en la inmensa riqueza que se produce al colocar horizontalmente y con énfasis articulatorios conocimientos que devienen y se generan de procesos diferentes (académicos y tradicionales o locales por ejemplo). La apropiación de la tecnología occidental por parte de los indígenas y la postura explicita desde la academia a promover interacciones interculturales colaborativas, de acompañamiento que contribuyan con la autonomía y 
descolonización de los procesos entre las culturas locales y las envolventes parecen resultar en compromisos y procesos de vida donde ambas partes pueden beneficiarse inmensamente. Creemos que esa es la única trocha fructífera cuando se trata de territorios y espacios indígenas.

\section{BIBLIOGRAFÍA}

Aguilera V. 2012 - Sombras chinescas en los títulos de propiedad colectiva sobre los hábitats y tierras indígenas en Venezuela. [En ligne : http://csr-eltopoobrero.org/?p=1901].

Caballero H. 2007 - La Demarcación de Tierras Indígenas en Venezuela. Revista Venezolana de Economía y Ciencias Sociales 13 (3) : 189-208.

Caballero H. \& Zent E. (Ed.) 2006 - Volumen especial sobre cartografias indígenas. Antropólogica 105-106:1-203.

Carlson T. \& Maffi L. (Ed.) 2004 - Ethnobotany and Conservation of Biocultural Diversity. Bronx, N.Y., The New York Botanical Garden. (Advances in Economic Botany).

Chapin M. \& Threlkeld B. 2001 - Indigenous Landscapes: A Study in Ethnocartography. Washington, D.C., Center for the Support of Native Lands.

Clarac N.G. 1983 - Las Comunidades Indígenas del País: núcleos fecundos para un proceso agrario autogestionario basado en el ecodesarrollo y etnodesarrollo. Caracas, Instituto de Agrario Nacional.

COIAM 2014 - Comunicado de la Coordinadora de Organizaciones Indígenas de la Amazonía Venezolana sobre el proceso nacional de demarcación de hábitat y tierras indígenas a los 15 años de aprobación de la Constitución Nacional. [En ligne http://laboratoriosdepaz.org/comunicado-de-la-coordinadora-deorganizaciones-indigenas-de-la-amazonia-venezolana-sobre-el-proceso-nacional-dedemarcacion-de-habitat-y-tierras-indigenas-a-los-15-anos-de-aprobacion-de-la-constituci/].

Ellen R.F. \& Harris H. 2000 - Introduction. In Ellen R., Parkes P., \& Bicker A. (Ed.) Indigenous Environmental Knowledge and its Transformations. Amsterdam, Harwood Academic Publishers : 1-33.

Escobar A. 1995 - Encountering Development: The Making and Unmaking of the Third World. Princeton, Princeton University Press.

Gaceta Oficial Año CXXVIII, X N 37.2573 de agosto 2001 - Decreto Presidencial Nro. 1392, Comisión Nacional de Demarcación del Hábitat y Tierras de los Pueblos y Comunidades Indígenas.

Gaceta Oficial Año CXXXVIII, V № 39.62425 de febrero de 2011 - Decreto Nro. 7.855, mediante el cual se reforma la Comisión Nacional de Demarcación del Hábitat y Tierras de los Pueblos y Comunidades Indígenas.

García Hierro P., Hvalkof S. \& Gray A. 1998 - Liberation through Land Rights in the Peruvian Amazon. Copenhagen, IWGIA. (Document ; 90).

Hunn E.S. 1999 - The Value of Subsistence for the Future of the World. In Nazarea V.D. (Ed.) Ethnoecology: Situated Knowledge/Located Lives. Tucson, University of Arizona Press : 23-36. IIED (International Institute for Environment and Development) 2006 - Mapping for Change: practice, technologies and communication. Participatory Learning and Action Nro. 54. 
Jiménez S. \& Perozo A. (Ed.) 1994 - Esperando a Kuyujani: Tierras, Leyes y Autodemarcación. Encuentro de comunidades Ye'kuanas del Alto Orinoco. Caracas, Asociación Otro Futuro, Gaia, IVIC.

KUYUJANI, Organización Indígena de la Cuenca del Caura 1998 - Territorio Ye’kwana-Sanema del Caura. Ciudad Bolívar: Kuyujani.

Ley Orgánica de Pueblos Indígenas (LOPI) 2005 - República de Venezuela.

Mansutti A. 2006 - La demarcación de territorios indígenas en Venezuela: Algunas condiciones de funcionamiento y el rol de los antropólogos. Antropológica 105-106 : 13-39.

Mattei-Müller M-C. 1994 - Diccionario Ilustrado Panare-Español/Índice Español-Panare. Caracas, Comisión Nacional Quinto Centenario.

Nazarea V.D. 1999 - A View from a Point: Ethnoecology as Situated Knowledge. In Nazarea V.D. (Ed.) Ethnoecology: Situated Knowledge/Located Lives. Tucson, University of Arizona Press : 3-20.

ORPIA et al. 2011 - Organizaciones indígenas de Amazonas se pronuncian ante el decreto de reestructuración de la Comisión Nacional de Demarcación de Tierras Indígenas.

Pérez Ruíz M.L. 2016 - La traducción y la hibridación como problemas para una interculturalidad autónoma, colaborativa y descolonizadora. LiminaR 14 (1) : 15-29.

Posey D. (Ed.) 1999 - Cultural and Spiritual Values of Biodiversity. London, Intermediate Technology Publications.

Quatra M.M. \& J. Liye, V. M. Liye, T. Jono, Á. Jelani, G. Jelani, L. Juae, J. Mölö, W. Melomaja, S. Jelani, B. Ijtë, E. Juainkoa, J. Rois, N. Caicedo, R. Andrade. 2008 - Bajkewa Jkwïkïdëwa-Jya Jodï IneDodo Ine. Diccionario Básico Castellano-Jodii. Caracas, Ediciones IVIC.

Republica de Venezuela. 1999 - Constitución Bolivariana.

Sociedad Homo et Natura 2012 - Sí son chimbos los títulos entregados a los pueblos indígenas Yukpa y Barí. [En ligne : http://www.aporrea.org/desalambrar/a137484.html].

Silva N. 2012 - Poster Reconocimientos Territoriales Indígenas Venezuela-Colombia Presentado en las VII Jornadas de Investigación de la UNEG (Universidad Nacional Experimental de Guayana) realizadas entre el 26-29 de Junio 2012.

Surrallés A. \& García Hierro P. (Ed.) 2004 - Tierra Adentro: Territorio Indígena y percepción del entorno . Copenhague, IWGIA. (Documento ; 39).

Tillett A. 2012 - Venezuela. In Mikkelsen C. El Mundo Indígena. Copenhague, IWGIA : 126-136.

VTV Venezolana de Televisión 2013 - Etnias indígenas reciben títulos de demarcación de hábitat y tierras. [En ligne : http://www.vtv.gob.ve/articulos/2013/03/27/etnias-indigenas-reciben-titulosde-demarcacion-de-habitat-y-tierras-1190.html].

Zent E. Ecogonía II. 2014 - Visiones alternativas de la biosfera en la América Indígena ¿Utopía o continuum de una noción vital? Etnoecológica 10 (7) : 1-21. [En ligne : http:// www.etnoecologica.com.mx/index.php/2014-04-19-16-08-19/volumen-X-ano-2014]

Zent E. \& Zent S. 2002 - Impactos Ambientales Generadores de Biodiversidad: Conductas Ecológicas de los Hotï de la Sierra Maigualidad del Amazonas Venezolano. Interciencia. 27 (1) : 9-20. [En ligne : http://www.interciencia.org/v27_01/index.html].

Zent E. y Zent S. 2004 - Amazonian Indians as Ecological Disturbance Agents: the Hotï of the Sierra Maigualida, Venezuelan Amazon. In Carlson T. \& Maffi L. (Ed.) Ethnobotany and Conservation 
of Biocultural Diversity. Bronx, N.Y., The New York Botanical Garden : 79-112. (Advances in Economic Botany).

Zent S. 2009 - Traditional Ecological Knowledge (TEK) and Biocultural Diversity: A Close-up Look at Linkages, Delearning Trends, and Changing Patterns of Transmission' In Bates P., Chiba M., Kube S. \& Nakashima D. (Ed.) Learning and Knowing in Indigenous Societies Today. Paris, UNESCO : 39-58.

Zent S. \& Zent E. 2006/2008 - Más allá de la Demarcación de Tierras Indígenas: Comparando y Contrastando las Etnocartografías de agricultores y cazadores-recolectores. Antropológica 105-106 : 67-98.

Zent E., Zent S. \& Marius L. 2004 - Autodemarcando la Tierra: Explorando las Ideas, los Árboles y Caminos Hotï. Boletín Antropológica 58 (2) : 313-338. [En ligne : http://www.saber.ula.ve/ bitstream/123456789/18498/1/articulo4.pdf].

Zent S., Zent E. \& Quatra M. - Palabras y Paisaje: El lenguaje del espacio entre los Jodi. Ponencia presentada en el simposio « Nombres de Lugares y Espacializaciones del Tiempo: Construcción del Espacio y Procesos de Significación en el Pasado y el Presente », V Reunión de Teoría Arqueológica en América del Sur, Universidad Central de Venezuela, Caracas, Venezuela. 21-25 de junio de 2010.

Zent S., Zent E. y Lucas Juae Molo 2011 - Un largo y sinuoso camino: breve historia de la autodemarcación territorial Jodï en su décimo aniversario. In Bello L.J. (Ed.) El Estado ante la Sociedad Multiétnica y Pluricultural: Políticas Públicas y Derechos de los Pueblos Indígenas en Venezuela (1999-2010). Copenhagen, IWGIA : 97-117.

\section{NOTAS}

1. Para más información sobre el concepto y propósito de la etnocartografía véase Zent y Zent 2006-2008 así como para cierto contexto histórico latinoamericano, también Caballero este volumen

2. Vale mencionar que tanto Héctor como José eran jefes de las comunidades respectivas cuando se inició el proyecto, y aunque estuvieron involucrados activamente durante una primera etapa luego disminuyeron notablemente su participación. Por otra parte, Lucas y Pablo asumieron la coordinación de una manera integral y sostenida desde el principio hasta el final.

3. Esta división de trabajo se refiere más bien a la fase de recolección y transcripción de datos de campo, mientras que la depuración y sistematización de la base de datos, preparación y georeferenciación de los mapas finales y elaboración de informes fueron realizados necesariamente por el personal del IVIC.

4. Según requisito establecido por la CNDHTI, las solicitudes de demarcación/titulación deben estar respaldado por la firma y huella de cada habitante de la zona y solo permiten la firma o huella de personas debidamente ceduladas (es decir, con documento de identidad). En vista de que solo una persona de los 300 habitantes de Caño Iguana tenía cédula en aquel momento, tuvimos que solicitar el operativo.

5. Esta organización o red agrupa unos 20 organizaciones indígenas de los Estados Amazonas y Bolívar, incluyendo ORPIA, KUBAWY, HORONAMI, OIPUS, KUYUNU, OMIDA, Madoya Huarija, OPUHJ, Cabildo Inga, OIYAPAM, OPIJKA, Organización Piaroa de Manapiare, RAJIA, UCYABYRN, KUYUJANI (Alto Orinoco), KUYUJANI (Caura), Asamblea de Pueblo E’ñepá, OcIUSPA, CONIVE y Estudiantes de Tauca.

6. Según este autor, han habido facciones dentro de las fuerzas armadas nacionales y del oficialismo opuestas a la entrega de grandes extensiones de tierra a los indígenas desde el tiempo 
de la asamblea constituyente. Por otra parte, la noción de otorgar terrenos amplios a los indígenas, o cualquier otro grupo, parece ser contradictorio a la política agraria bolivariana que ha buscado erradicar los latifundios. Este análisis tiene eco en los comentarios del otrora VicePresidente Elías Jaua, citados en Tillett 2012.

7. Los expedientes pendientes son: de los pueblos Uwottüja y Jivi del Municipio Autana (Organizaciones OIPUS y OPIJKA) en la Cuenca del Río Sipapo y Orinoco Medio; el del pueblo Yabarana-Multiétnico del Municipio Manapiare (Organización OIYAPAM) en la Cuenca del Río Parucito; el de los pueblos Ye'kuana - Sanemá del Municipio Manapiare (Organización KUYUNU) en el Alto Ventuari; el del pueblo Ye'kuana del Municipio Alto Orinoco (Organización KUYUJANI Originario); y el del pueblo Yanomami del Municipio Alto Orinoco (Organización HORONAMI).

8. Entre los Jodï el alfabeto utilizado para el mapa devino en la publicación del primer diccionario Jodi-Castellano de 1,500 palabras (Quatra et. al. 2008). El alfabeto es producto de dos talleres de dos semanas de duración cada uno realizados en Kayamá en Abril 2002 y Octubre 2005 con la participaron de todos los maestros Jodï de la comunidad, algunos adultos mayores, dos monjas misioneras, el Padre de la comunidad, Marcelo Quatra y el primer autor de este trabajo como asesor lingüístico. Las decisiones sobre la ortografía del alfabeto y las reglas de redacción a utilizarse fueron tomadas consensualmente por los Jodï presentes. De modo similar, el alfabeto Eñepa fue desarrollado consensualmente en Abril 2002 a través de un taller en donde participaron el primer autor de este trabajo, el Padre Quatra y un grupo de maestros e interesados Eñepa. Cabe destacar que este alfabeto guarda algunas diferencias con el alfabeto presentado en Mattei-Müller, M-C. 1994. En Junio 2014 se dio un segundo taller, con el propósito de revisar y evaluar el alfabeto original con miras a mejorarlo. Actualmente, los maestros Jodï y Eñepa en Kayamá están enseñando los alfabetos desarrollados para el mapeo de sus tierras, para lo cual han producido algunas cartillas educativas.

9. En este contexto, entendemos el concepto de subsistencia en un sentido amplio como todos los insumos requeridos o deseados para la manutención y supervivencia del grupo en cuestión, incluyendo: alimentos, medicinas, viviendas, tecnología autóctona, artesanía, rituales, etc.

\section{RESÚMENES}

Este texto versa sobre algunos aprendizajes tanto prácticos como conceptuales que derivan de nuestra experiencia de participar en un proyecto de auto-demarcación de tierras indígenas en Venezuela. El proyecto involucraba la colaboración entre académicos del Instituto Venezolano de Investigaciones Científicas (IVIC) y comunidades locales de las etnias Jodï y Eñepa, y tuvo como objetivo la preparación de mapas comunitarios y la compilación de todos los documentos necesarios para solicitar los títulos de tierra ante el estado venezolano. El primer tema que tocamos se refiere a la importancia de las alianzas entre comunidades locales y actores externos (por ej., académicos) para navegar la ruta complicada de recaudos y tramites desde el reconocimiento teórico de los derechos territoriales hasta la tenencia concreta y efectiva de un terreno definitivo; tales articulaciones implican la integración de capacidades complementarias pero también la comprensión de percepciones o intereses disímiles. En segundo lugar, analizamos la ambigüedad del Estado en todo este proceso, reflejada en diversas contradicciones entre las leyes escritas y las practicas, los diferentes enfoques y actitudes de los múltiples agentes del estado a nivel regional y nacional, la inconsistencia en la aplicación de normativas o ausencia de ellas, el cambio recurrente de reglas, entre otros aspectos que han dificultado o impedido el 
llevar a feliz término el objetivo final de las demarcaciones indígenas: alcanzar los títulos y propiedades legales de sus territorios. Tercero, la realidad múltiple del mapa es evidenciada entre otros aspectos en una polisemia espacio-temporal, la cual nos obliga reconocer las maneras diferentes para apercibir y comprender el espacio y el tiempo entre los grupos no occidentales, discontinuos, en espiral o recurrentes por ejemplo. Por último, exploramos cómo la territorialidad indígena puede contribuir a una política de conservación biocultural. Concluimos con la observación de que los proyectos colaborativos de mapeo comunitario y demarcación de tierras en donde miembros de la(s) comunidad(es) local(es) participan activamente con actores académicos representa una vía prometedora para el avance de la investigación etnoecológica.

This paper reflects on practical and conceptual lessons acquired as a result of our participation in a project of self-demarcation of indigenous lands in Venezuela. The project was based on a collaboration between academics from the Venezuelan Institute for Scientific Research (IVIC) and local communities of the Jodï and Eñepa ethnic groups. The goal was to prepare maps of community lands and compile all of the documentation required to petition the Venezuelan State for the land title. The first point proves the importance of alliances among local communities and external actors (such as academy-trained researchers) in order to navigate the complicated route of ethno-cartographic documentation and bureaucratic motions that leads from the theoretical recognition of territorial rights to the real and effective tenure over the land. Such collaborations imply the integration of complementary capabilities but also the mutual understanding of dissimilar perceptions and interests. In the second place, we analyze the ambiguity of the State in regards to Indian land rights recognition throughout the Bolivarian constitutional period, as reflected in various contradictions between written laws and legal practices, the separate actions and attitudes of different government agents at regional and national levels, the inconsistencies in the institutional authorities and application of norms established to promote the demarcation process, the legal lacunae or recurrent changes in the rules regarding the petition of land rights recognition, among other aspects that have impeded reaching the final goal of indigenous land demarcations: obtaining legal title or ownership rights over their lands. Third, the multiple realities of the map are evidenced by spatial-temporal polysemy, which have forced us to recognize the different ways of perceiving and experiencing space and time among non-western peoples, for example internalized in daily life yet externalized in symbolic representations at the same time. Lastly, we explore how indigenous territories can contribute to biocultural conservation policy. We conclude with the observation that collaborative projects geared toward community mapping and land demarcation, in which local community members and academic researchers participate actively in tandem, offer a promising venue for advancing ethnoecological research.

Cet article traite des apprentissages pratiques et conceptuels acquis de notre participation à un projet d'auto-démarcation de terres indigènes au Venezuela. Le projet se fondait sur une collaboration entre des universitaires de l'Institut Vénézuélien de Recherches Scientifiques (IVIC) et des communautés locales des ethnies Jodï y Eñepa, réunis avec l'objectif de préparer les cartes communautaires et réunir toute la documentation nécessaire à la demande de titres fonciers à l'Etat vénézuélien. Nous montrons d'abord l'importance des alliances entre communautés locales et acteurs externes (chercheurs inclus) pour naviguer sur la route difficile des formalités administratives et exigences documentaires, depuis la reconnaissance théorique des droits territoriaux jusqu' à l'obtention effective d'un titre de propriété définitif. Une telle collaboration exige d'intégrer des compétences complémentaires mais demande aussi la compréhension mutuelle de perceptions et d'intérêts différents. Dans un deuxième temps, nous analysons l'ambiguïté de l'État face à la reconnaissance des droits des amérindiens par la Constitution, manifestée par des contradictions entre lois écrites et pratiques, des attitudes et actions divergentes de la part de nombreux acteurs gouvernementaux à l'échelle régionale et 
nationale, une incapacité à faire appliquer les normes établies pour mener les processus de démarcation, le changement récurrent des règles, ou leur absence, parmi les motifs qui ont rendu difficile, voire empêché, le but initial des démarcations indigènes: obtenir les titres légaux de la reconnaissance des droits des amérindiens sur leurs territoires.

Troisièmement, la réalité multiple de la carte se manifeste, entre autres, par une polysémie spatiotemporelle; elle nous oblige à reconnaître qu'il existe des manières différentes de percevoir et de pratiquer l'espace et le temps dans les peuples non occidentaux, comme celles présentées par exemple dans cet article. Enfin, nous cherchons à voir comment les territorialités indigènes peuvent contribuer aux politiques de conservation bioculturelle. Les projets collaboratifs de cartographie communautaire et de démarcation de terres, où les membres des communautés locales participent activement et de concert avec les chercheurs universitaires, constituent une voie prometteuse pour la recherche en ethnoécologie.

\section{ÍNDICE}

Índice geográfico: Venezuela, Amazonie

Mots-clés: droits territoriaux indigènes, autodémarcation territoriale, recherche-action collaborative, alliances entre chercheurs et populations locales, ambiguïté de l'Etat, dysglossie géographique, conservation bioculturelle, ethnoécologie

Palabras claves: derechos de tierras indígenas, auto-demarcación territorial, investigaciónacción colaborativa, alianzas académicas-locales, ambigüedad del Estado, disglosia geográfica, conservación bio-cultural, investigación etnoecológica

Keywords: indigenous land rights, territorial demarcation, collaborative action research, academic-local alliances, state ambiguity, geographic diglossia, biocultural conservation, ethnoecological research

\section{AUTORES}

\section{STANFORD ZENT}

Investigador Titular, Antropólogo, szent@ivic.gob.ve

\section{EGLEÉ L. ZENT}

Investigadora Asociada Titular, Etnoecóloga, elzent@ivic.gob.ve

Laboratorio de Ecología Humana, Centro de Antropología

Instituto Venezolano de Investigaciones Científicas,

Panamericana Km 11, Altos de Pipe, Miranda, Venezuela

\section{LUCAS JUAE MÖLÖ}

molojawa16@gmail.com

Asociación Civil Jodï JodenaU

Coordinador de las etnia indígena Jodï

\section{PABLO CHONOKÓ}

Coordinador de la etnia indígena Eñepá,

San José de Kayama, Sierra de Maigualida Municipio Cedeño, Bolívar 